\title{
Article \\ Ecological Study of Fractures in Paediatric Melanesian Communities with Varying Endemic Environmental Fluoride Exposure
}

\author{
Webb Elizabeth ${ }^{1}$, Ahmad Elmansouri ${ }^{2}$, Rebecca Ross ${ }^{2}$, Michael Clynes ${ }^{2}$, Jenny Tangis ${ }^{3}$, Carol Stewart ${ }^{4}$ (i) \\ and Elaine M. Dennison $1,2, *$ \\ 1 School of Biological Sciences, Victoria University of Wellington, Wellington 6011, New Zealand; \\ Elizabeth.Webb@vuw.ac.nz \\ 2 MRC Lifecourse Epidemiology Centre, Southampton SO16 6YS, UK; ahmadelmansouri@hotmail.co.uk (A.E.); \\ rebecca.ross15@nhs.net (R.R.); mc@mrc.soton.ac.uk (M.C.) \\ 3 Ministry of Health, Private Mail Bag 009, Port Vila, Vanuatu; jeno833@gmail.com \\ 4 School of Health Sciences, Massey University, Wellington 6140, New Zealand; C.Stewart1@massey.ac.nz \\ * Correspondence: emd@mrc.soton.ac.uk
}

\section{check for} updates

Citation: Elizabeth, W.; Elmansouri, A.; Ross, R.; Clynes, M.; Tangis, J.; Stewart, C.; Dennison, E.M. Ecological Study of Fractures in Paediatric Melanesian Communities with Varying Endemic Environmental Fluoride Exposure. Osteology 2021, 1, 132-140. https://doi.org/10.3390/ osteology1030014

Academic Editor: Rodolfo

Gómez Bahamonde

Received: 14 May 2021

Accepted: 27 July 2021

Published: 30 July 2021

Publisher's Note: MDPI stays neutral with regard to jurisdictional claims in published maps and institutional affiliations.

Copyright: (c) 2021 by the authors. Licensee MDPI, Basel, Switzerland. This article is an open access article distributed under the terms and conditions of the Creative Commons Attribution (CC BY) license (https:// creativecommons.org/licenses/by/ $4.0 /)$.

\begin{abstract}
Introduction: Osteoporotic fracture is a major public health burden worldwide, causing significant mortality and morbidity. Studies that have reported bone health in areas of high endemic fluorosis have commonly reported adverse skeletal, as well as dental effects. Vanuatu, sited in the Pacific, and never previously studied with regard to bone health, has six continuous degassing volcanoes on separate islands, resulting in a natural experiment for an ecological study of relationships between naturally occurring fluoride exposure and fracture incidence in paediatric populations. Methods: This ecological study recruited 1026 lifetime residents of the rural Vanuatu islands. A short questionnaire was administered detailing gender, age, and residential history. Participants were asked if they had broken a bone and, if so, were asked to mark its location on a questionnaire manikin. Dental fluorosis was assessed using Dean's index. Community drinking-water samples were sampled for fluoride concentration. Results: The measured water fluoride concentration and recorded dental fluorosis displayed expected gradients from Aneityum (low) to Ambrym (high) $(p<0.001)$. The age of participants studied varied from 7.8 (SD 1.2) in Aneityum to 10.6 (3.7) in Lamap/Uliveo. The highest self-reported fracture rates were recorded in the area with medium fluoride levels (Lamap/Uliveo), where $14.9 \%$ of boys and $15.6 \%$ of girls sampled reported a fracture. In Ambrym, where the mean age of participants was similar, corresponding fracture rates were $4.5 \%$ and $2.6 \%$. ( $p$ value for differences all $<0.05$ ). Conclusions: Reports of fractures were common in children living in Vanuatu, but demonstrably higher in Lamap, the region with medium fluoride concentrations, rather than Ambrym which had very high rates of naturally occurring fluoride levels. Longer term studies that report validated fracture after peak bone mass acquisition are required.
\end{abstract}

Keywords: bone; fluoride; fracture; endemic; volcano; epidemiology

\section{Introduction}

Osteoporotic fracture is a major public health burden worldwide, causing very significant mortality and morbidity [1]. Ethnicity is known to be a significant factor in the determination of fracture risk, and where data are available, Pacific populations appear relatively protected against osteoporosis and osteoporotic fracture, relative to Caucasian populations [2]. While the impact on bone health of exposure to high fluoride concentrations through community water fluoridation programmes has been controversial, studies that have reported bone health in areas of high endemic fluorosis have commonly reported adverse skeletal, as well as dental effects [3-14]. Most of these studies have been conducted in India, Turkey, Saudi Arabia and Iran, with the first reports from skeletons excavated following the Vesuvius eruption in 79AD [15]. 
While naturally high fluoride concentrations are most often associated with groundwater provinces [16], volcanoes may also be significant sources of fluorine. Fluorine is emitted as gaseous hydrogen fluoride (HF) both during and between eruptions. HF contaminates downwind areas through both wet and dry deposition and can also adsorb into volcanic ash particles in explosive volcanic eruptions. Here, it can react with mineral surfaces to form readily soluble forms of fluorine such as sodium fluoride, and poorly soluble forms such as calcium fluoride and aluminium fluoride [17]. Areas of persistent volcanic degassing associated with high local fluoride contamination include Iceland, regions of Italy, countries along the East African Rift zone and Vanuatu [18].

Vanuatu, sited in the southwest Pacific, has six active volcanoes on separate islands from the north to the south of the island chain [19], monitored by the Vanuatu Meteorology and Geo-hazards Department (www.vmgd.gov.vu, accessed on 27 July 2021). Ambrym Island, located approximately in the centre of the archipelago, contains the most vigorously degassing volcano on Earth [20]. In a volcanogenic setting, the environment is often contaminated with unknown levels of fluoride with locally grown foods, accidental soil and air ingestion likely methods of additional fluoride consumption [19]. However, community drinking waters are considered to be the main source of fluoride intake [21].

Endemic skeletal fluorosis can have a wide variety of radiographic appearances, including calcification and/or ossification of the attachments of soft-tissue structures to thebones, osteosclerosis, osteopenia, growth lines and metaphyseal osteomalacic zones [22]. It has been suggested that very high fluoride intakes may be detrimental to bone health through effects on the endocrine system (parathyroid and thyroid hormones), as well as through direct uptake into the skeletal matrix where, although it may increase bone density, it may also increase bone brittleness and hence fracture risk [23,24]. Most of the available studies report findings in adults though some previous studies have reported observations in children in India and Iran [3,12].

The aims of this study were therefore: (1) to report fracture rates among Pacific Island children participating in a study of dental health in Vanuatu, a tropical archipelago in Melanesia containing rural areas of varying endemic fluoride concentration, where no previous fracture incidence data are currently available; and (2) relate fracture rates to fluoride exposure in an ecological study design. We hypothesized that populations exposed to very high rates of naturally occurring fluoride may display higher fracture rates.

\section{Methods}

This cross-sectional study recruited participants aged $4-17$ years $(n=1026)$, lifetime residents of rural islands: northwest Ambrym, southeast Malekula (including Avock Island), Uliveo Island in the Maskelyne Islands Group and Aneityum Island. Schools were selected to represent differing fluoride-exposure distances from the active volcanic cones of Benbow and Marum on Ambrym Island and the known high-fluoride contamination of the local environment [19]. Children who were not currently enrolled in school were also included. Children in this study who were from villages in northwest Ambrym, were closest to the volcanic activity of Benbow and Marum, which were located in the centre of the island, up to $20 \mathrm{~km}$ away. Children at school on Uliveo Island were $41 \mathrm{~km}$ downwind (of the prevailing southeasterly trade winds) from Ambrym's active volcanic vents. Children who attended schools on the southeast coast of Malekula Island, in Lamap Village and Namaru School on Avock Island were 37-45 km downwind from Ambrym's active vents. Children who participated from Aneityum Island, in the south of the archipelago, were not influenced by the active volcanic vents of Ambrym, nor from the consistent volcanic activity of Yasur on the neighbouring island of Tanna, $80 \mathrm{~km}$ to the north.

\section{Clinical Assessment}

Gender, age and village details were collected. Fluorosis severity was established using Dean's index applied to anterior teeth [25]. Dean's Index (DI) describes the severity of dental fluorosis on a numeric scale. Fluorosis is described as 'questionable (1)' if 
unclear; 'very mild (2)' and 'mild (3)' as white spot enamel lesions and streaks occur; and 'moderate (4)' and 'severe (5)', as brown staining and pitting is observed on the tooth surface. Examinations were conducted in classrooms with teachers present, by one examiner, calibrated to an international standard for Dean's index (fluorosis). Data was paper recorded in the classroom at each school, then transferred to an Excel computer spreadsheet in New Zealand. Questionnaires (translated into the national language of Bislama) were used to ask participants if they had broken a bone, and if so were asked to mark the location of the fracture on a questionnaire manikin. Fractures were then classified according to site by two reviewers.

\section{Fluoride Measurement}

Community drinking-water samples were collected from schools and villages to establish fluoride concentrations in local drinking water supplies. Water samples were collected in clean, pre-rinsed plastic bottles and stored in a fridge. The samples were transported back to New Zealand, imported with the necessary biosecurity permits, then couriered directly to Hills Laboratories, Hamilton; an internationally accredited laboratory (International Accreditation New Zealand). Fluoride concentrations were determined in the water samples at the laboratory using direct measurements by ion selective electrode methods (APHA Method 4500-F-C, 22nd edition 2012). The detection limit was $0.05 \mathrm{mg} / \mathrm{L}$ F. Results were combined and an average determined for each area.

\section{Statistical Methods}

We performed statistical analyses using SPSS 26V software (available at: https: / / www.ibm.com/uk-en/products/spss-statistics, accessed on 27 July 2021). Means and SDs were calculated and $t$ tests and ANOVA tests were used to test the differences in fluoride levels and fracture rates between the populations studied.

\section{Results}

We surveyed 192 children (118 boys and 74 girls) in an area of low fluoride concentration (Aneityum); 524 children (255 boys and 269 girls) in an area of medium fluoride concentration (Lamap/Uliveo); 225 children (110 boys and 115 girls) in an area of high fluoride exposure (Ambrym). The study areas are shown in Figure 1. Fluoride concentration levels detected in drinking-water samples collected had been previously reported [26], with the lowest levels recorded on Aneityum Island. Samples from Lamap Village and the southeast of Malekula Island had medium F concentrations while samples collected from the northwest of Ambrym had the greatest range of variability, but also the highest levels. Average F levels for each of the areas were as follows: Aneityum Island, $0.05 \mathrm{mg} / \mathrm{L}$; southeast Malekula, $0.27 \mathrm{mg} / \mathrm{L}$; Uliveo, $0.66 \mathrm{mg} / \mathrm{L}$; and northwest Ambrym, $1.20 \mathrm{mg} / \mathrm{L}$. Student's t-tests showed that the differences in fluoride concentrations between areas were highly significant $(p<0.001)$. Fluorosis status could not be determined in 15 children who had very poor oral hygiene. Dental fluorosis incidence ranged from $0 \%$ in Aneityum, to $62 \%$ in Lolibulo village, Ambrym (Figure 2). 


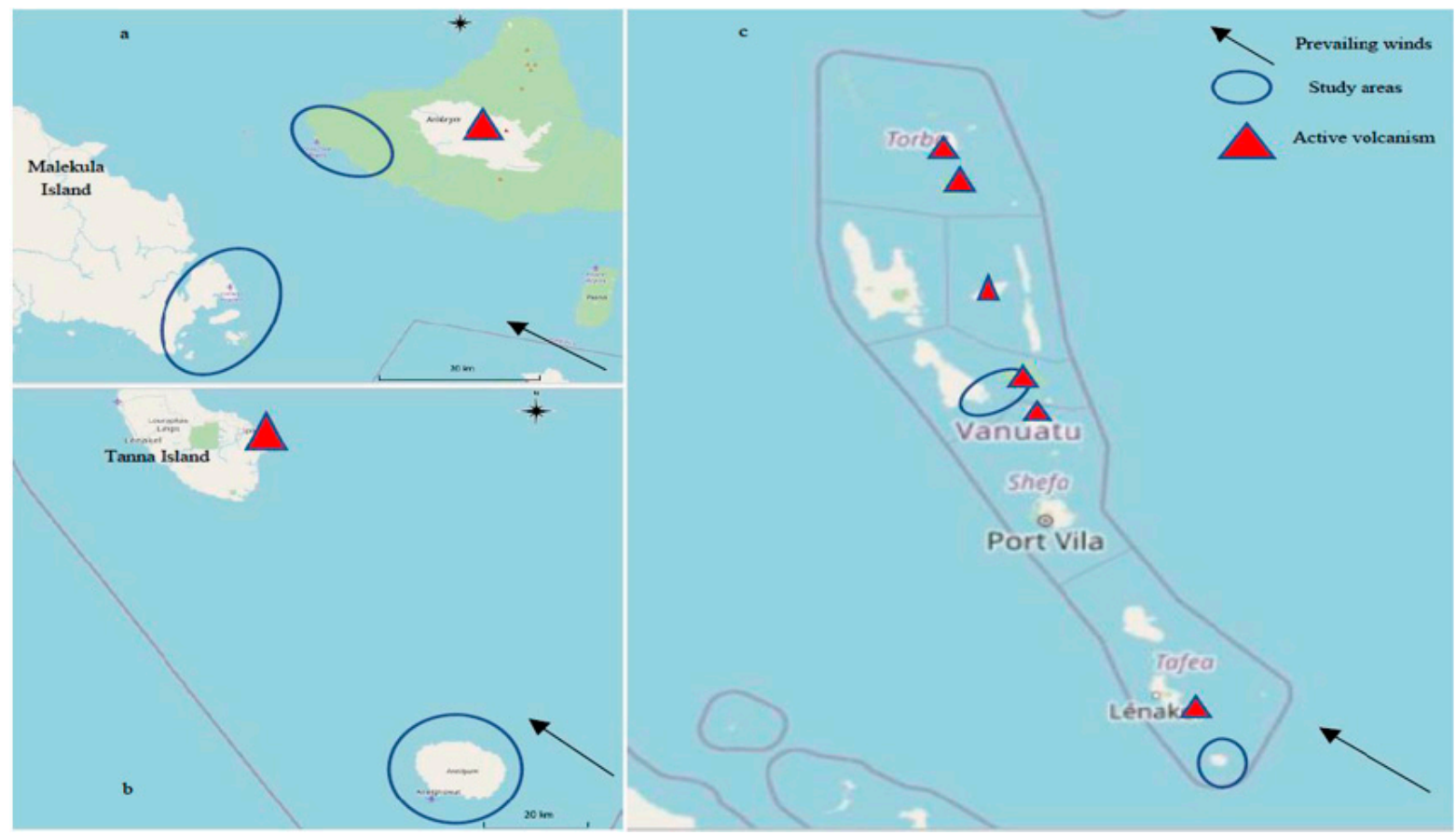

Figure 1. (a) Study areas of Ambrym, Malekula and Maskelyne Islands, south of Malekula. (b) Study area of Aneityum Island. (c) Map of Vanuatu showing study areas and active volcanism.

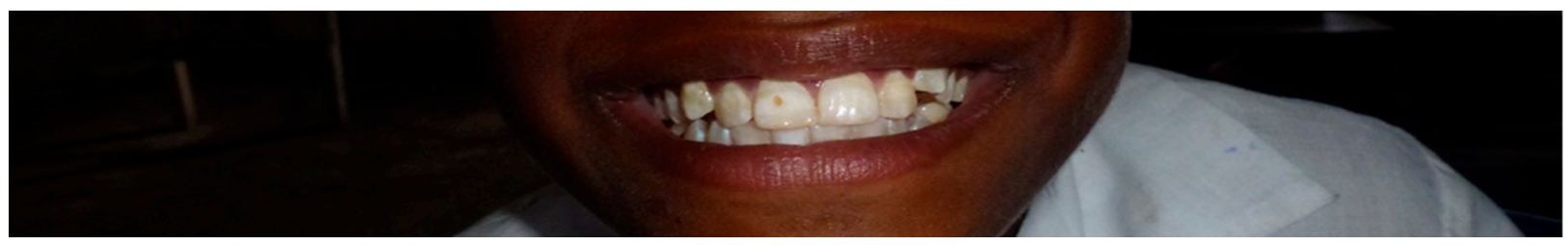

Figure 2. Dental fluorosis.

\subsection{Fracture Rates in Areas of Low, Medium and High Endemic Fluorosis}

The mean reported age of participants in each region is shown in Table 1 . This differed by location, with similar ages for two locations: 10.3 (SD 3.1) years in boys and 10.6 (3.7) years in girls in Lamap/Uliveo; and 9.53 (SD 3.0) years in boys and 10.2 (3.3) years in girls in Ambrym, but participants were younger at the third site. In Aneityum the mean age was 8.6 (SD 1.4) years in boys and 7.8 (SD 1.2) years in girls.

Table 1. Ages of boys and girls surveyed at each site, with reported fracture incidence.

\begin{tabular}{|c|c|c|c|c|c|c|}
\hline & \multicolumn{2}{|c|}{$\begin{array}{l}\text { Aneityum (Low Fluoride) } \\
\qquad \mathrm{N}=192\end{array}$} & \multicolumn{2}{|c|}{$\begin{array}{l}\text { Lamap (Medium Fluoride) } \\
\qquad \mathrm{N}=524\end{array}$} & \multicolumn{2}{|c|}{$\begin{array}{l}\text { AMBRYM (High Fluoride) } \\
\qquad \mathrm{N}=225\end{array}$} \\
\hline & $\begin{array}{c}\text { Boys } \\
N=118\end{array}$ & $\begin{array}{l}\text { Girls } \\
N=74\end{array}$ & $\begin{array}{c}\text { Boys } \\
N=255\end{array}$ & $\begin{array}{c}\text { Girls } \\
N=269\end{array}$ & $\begin{array}{c}\text { Boys } \\
\mathbf{N}=\mathbf{1 1 0}\end{array}$ & $\begin{array}{c}\text { Girls } \\
\mathrm{N}=115\end{array}$ \\
\hline Age (SD) years & 8.61 (SD 1.44) & 7.77 (1.15) & $10.3(3.13)$ & $10.6(3.73)$ & $9.53(3.03)$ & $10.15(3.32)$ \\
\hline $\begin{array}{c}\text { Reported } \\
\text { fracture rates } \\
(n, \% \text {, any site) }\end{array}$ & $\begin{array}{c}6 \\
4.6 \%\end{array}$ & $\begin{array}{c}4 \\
5.4 \%\end{array}$ & $\begin{array}{c}38 \\
14.9 \%\end{array}$ & $\begin{array}{c}42 \\
15.6 \%\end{array}$ & $\begin{array}{c}5 \\
4.5 \%\end{array}$ & $\begin{array}{c}3 \\
2.6 \%\end{array}$ \\
\hline
\end{tabular}


The highest self-reported fracture rates were on Lamap/Uliveo, where $14.9 \%$ boys sampled and $15.6 \%$ girls sampled reported a fracture. By contrast, rates on the other two islands were similar. In Aneityum, the youngest cohort of this study, $4.6 \%$ boys and $5.4 \%$ girls reported a fracture; while in Ambrym, $4.5 \%$ boys and 2.6\% reported a fracture ( $p$ for difference all <0.05).

\subsection{Location of Fracture}

Table 2 shows the self-reported fracture incidence by site, sex and location for all sites surveyed combined. Overall, 98 fractures were reported in our cohort of 1026 children. The vast majority of children reported only one fracture (data not shown). Although missing data were common, with many children reporting that they had broken a bone but failing to record the site (about 20\%). The forearm was the most commonly affected site reported, with approximately equal fracture rates for both boys and girls (26 boys and 31 girl of 57 children with recorded upper limb fractures). Fractures of the lower limb were recorded in more boys than girls ( 10 boys and 8 girls, of 18 children with recorded lower limb fractures).

Table 2. Fractures recorded by all participants $(n=1029)$ by recorded locations.

\begin{tabular}{ccc}
\hline & Boys & Girls \\
\hline Skull & $1(2 \%)$ & $1(2.0 \%)$ \\
UPPER LIMB $(\mathrm{n}=57)$ & & \\
Humerus & $1(2 \%)$ & $4(8.2 \%)$ \\
Forearm & $18(36.7 \%)$ & $15(30.6 \%)$ \\
Wrist & $6(12.2 \%)$ & $6(12.2 \%)$ \\
Hand & $1(2 \%)$ & $6(12.2 \%)$ \\
Pelvis & & $1(2 \%)$ \\
Patella & $1(2 \%)$ & $0(0 \%)$ \\
Lower leg & $1(2 \%)$ & $3(6.1 \%)$ \\
Ankle & $5(10.2 \%)$ & $4(8.2 \%)$ \\
& $3(6.1 \%)$ & $9(18.4 \%)$ \\
Unspecified & $12(24.5 \%)$ &
\end{tabular}

\section{Discussion}

In this study we reported self-recorded fractures among children living on three islands in Vanuatu with very different fluoride concentrations. Reports of fractures were common in these children, but three times higher on Lamap, the region with medium fluoride concentrations, rather than the area with very high rates of naturally occurring fluoride levels. The ages of the children were different at the three sites, making accurate comparison problematic, but the age difference between the area of very high and medium fluoride level was not statistically different. Furthermore, while fractures are self- reported in this study, it is not clear why reporting might be different on one island relative to the others. Migration between islands is uncommon, and so island of study most likely represents a good proxy of fluoride exposure. We therefore hypothesize that at this young age other factors, specifically risk-taking behaviour and accidents, play a greater role in fracture occurrence than fluoride incorporation into the skeleton. Longer-term studies are now required and should report validated fractures after peak bone mass acquisition and subsequently, and collect other relevant confounders such as the mechanism of fracture and calculated dietary calcium intake.

In addition to the points raised above, there are of course many other limitations in this study. Although hospital-validated records might be considered the gold standard in most studies, this is not necessarily the case in Vanuatu. Few islanders have access to hospital facilities, including radiography, with many needing to utilise traditional remedies [27]. Travel to the main hospitals on the islands of Efate and Santo Espiritu is not often affordable for rural dwellers who rely on access to $\mathrm{MOH}$ medivac services in emergency situations [28]. 
We therefore collected self-reported fractures and, as discussed above, do not believe that a systematic reporting bias was present. Specifically, children completed the questionnaire independently so we do not believe peer pressure or discussion would lead to reporting bias. This study measured an estimate of fluoride delivered in community drinking waters for this cohort of children, which is considered to be the largest intake of fluoride in a community setting [21]. It is difficult to characterise F concentrations in drinking waters given that (1) F in rainwater-fed samples varies widely, (2) that people obtain drinking water from diverse sources and (3) the lack of any routine monitoring. Our sampling was done as a one-off event and is therefore a further limitation in this study. However, the community drinking-water results for fluoride for samples, taken in 2013 and 2014, are similar to a small selection of samples taken in northwest Ambrym and Lamap, southeast Malekula in 2017 for a national oral health survey [29]. Additionally, the roof-fed rainwater samples taken in 2017 in Lamap were also variable due to the intermittent nature of tephra depositing, their strength and the trade winds carrying them. It was beyond the scope of this study to estimate the total environmental fluoride intake for the participants and it is likely that foods consumed from this region are contaminated with unmeasured levels of fluoride [19]. As discussed above, the age of participants varied by island; participants in Lamap were the oldest, but not significantly different to Ambrym, which recorded much lower fracture rates. Finally, the assessment of bone density in this group would have been helpful, but was not possible due to limited reliable power supplies.

Although we collected some dietary data in the form of food-frequency diaries, these were designed to give general information on the dietary patterns of this population and were not suitable for the calculation of calcium intake-further work is planned in this area. Initial review has confirmed that dietary patterns seem very similar across the islands. A future study also aims to collect more detailed information regarding the mode of fracture, associated trauma and falls, as well as more information on patterns of physical activity. Venesection would be very challenging in this setting, where electricity supplies are variable and refrigeration of samples impossible, preventing us from gaining information on PTH or vitamin D levels.

We did not find relationships between fluoride exposure and fracture in this ecological study of children. We hypothesise that physical activity and trauma may be more important in this age group, but further work that includes study of adolescents and adults in now warranted. Our findings accord with a study by Levy and colleagues [30] who considered relationships between fluoridation levels in Iowa and cortical bone measures assessed by peripheral QCT in 424 children. The number of children exposed to very high levels of fluoride is of course much lower, as this study was situated in the US, so it is difficult to draw direct comparisons and the authors acknowledged the need for longer follow up in their work. In another Turkish study of early postmenopausal women, BMD was reported to be high among women living in areas of endemic fluorosis [31].

The assessment of bone density and microarchitecture is unusual in studies of endemic fluorosis exposure. In one Tanzanian study by Jarvis and colleagues [7], skeletal fluorosis was classified as any of genu valgum/varum, sabre tibia (anterior bending and thickening of the tibia), kyphosis/scoliosis (with no other obvious explanation) with or without neurological signs of sensory loss and muscle wasting. In this survey using this classification, skeletal fluorosis reached $10 \%$ by 15 years of age (5.7\% by 9 years of age), with the condition more common in males. The assessment of skeletal fluorosis would classically be conducted by radiograph, a gold standard which could not be applied to this population for practical and ethical reasons. In a rare study that used radiographs, sited in Ethiopia, Melaku reported that after adjustment for other factors, males were 2.5 times more likely to have skeletal fluorosis reported in this way, though age was the stronger risk factor; older people aged 55 years and above had about 20 times higher risk than young adults aged 15-24 years [8].

By contrast to studies that have suggested relatively low levels of skeletal fluorosis in children, studies of adults living in areas of high naturally occurring fluoride have 
suggested very high levels of skeletal fluorosis; one study in Iran reported that skeletal fluorosis was observed in 54.5\% of the cohort aged 71 years and above and was more commonly found in females than males [3]. Another cohort study in India conducted by Ramesh and colleagues reported that skeletal fluorosis did not identify any individuals with skeletal fluorosis under the age of 30 years, but reported that in older adults there were strong correlations between skeletal and dental fluorosis [4].

Some researchers, reporting differences in the prevalence of skeletal fluorosis among areas with similar levels of fluoride exposure, have investigated possible explanations. Liu and colleagues surveyed Chinese residents, reporting that, in adults, protective factors against skeletal fluorosis included storing water in a ceramic tank and ingesting fruits, vitamin A, thiamine and folic acid. [6]. It has been suggested that dietary calcium intake may moderate the impact of endemic high levels of fluoride on the skeleton [31]; in our study we collected food diaries which did not suggest systematic differences between dietary calcium intake across the sites, but further research is underway. These factors warrant further study in these populations.

It has been suggested that fluoride may exert its effects on the skeleton partly by inducing secondary hyperparathyroidism [24]. In a Turkish study, serum PTH levels were increased in subjects exposed to high levels of fluorosis. Researchers have postulated that fluoride, by interfering with calcium balance, may be the cause of secondary hyperparathyroidism. In another study by Teotia and colleagues, secondary hyperparathyroidism was present in $25 \%$ of participants with skeletal fluorosis, who also suggested it might represent a compensatory attempt to maintain a normal extracellular ionized calcium equilibrium [23].

In a detailed review, Teotia and colleagues reviewed the literature surrounding relationships between dietary calcium intake and fluoride [32]. They summarised epidemiological studies performed in the 1960s, setting adequate and inadequate dietary calcium intake at dietary calcium, $>800 \mathrm{mg} /$ day, and inadequate, $<300 \mathrm{mg} /$ day, respectively. The toxic effects of fluoride were severe and more complex and the incidence of metabolic bone disease and bony leg deformities was greater (>90\%) in children with calcium deficiency, as compared to $<25 \%$ in children with adequate calcium who largely had an osteosclerotic form of skeletal fluorosis with minimal secondary hyperparathyroidism. We might expect that the metabolically active and hence vascular bones in children accumulate fluoride at a faster and greater rate than adults. Certainly, in calcium-deficient children the toxic effects of fluoride manifest, even at marginally high ( $>2.5 \mathrm{mg} /$ day) exposures to fluoride. Furthermore, fluoride toxicity also exaggerates the metabolic effects of calcium deficiency on bone.

Much of the initial research into skeletal fluorosis has been published by researchers in India. Hence, in a detailed exposition of skeletal fluorosis in 1945 [12], Khan and colleagues eloquently reported that skeletal fluorosis was much less common than dental fluorosis, but primarily manifests itself as cortical thickening, calcification of ligaments, and periosteal new bone formation, with the skull and spine particularly affected. Even in this early work they remarked on the possible protection from skeletal effects from dietary intake of vitamin $C$ and calcium. In a subsequent very large epidemiological survey conducted in the 1960s of approximately 46,000 children aged 5-17 in the Punjab, skeletal fluorosis was very rare, reported as only present in $2.5 \%$ in villages exposed to fluoride levels of 0.9 to $2.5 \mathrm{mg} / \mathrm{L}$ [13]. Hence while skeletal fluorosis in childhood is rare, some case reports do exist in the literature [33].

In conclusion, self-reported fracture was common in this group of children, though not clearly related to fluoride exposure at these ages. This study represents the first report of fracture prevalence among these Melanesian paediatric populations and complements similar work in rural India, Turkey, Iran and Saudi Arabia. Further work is now underway to ascertain how fractures are sustained as, anecdotally, trauma is commonly reported in this group. In our sample, we found the highest rates of fracture among children exposed to moderate rather than high levels of fluoride in the environment, but longer term follow 
up in larger samples is now indicated, with more detailed musculoskeletal phenotyping, and a wider range of dietary information collected to allow for the calculation of dietary calcium intake, in addition to studies in older adults, in whom dental and skeletal fluorosis is more common.

Author Contributions: W.E., E.M.D. and C.S. conceived the study; J.T. provided input to study execution; W.E. and C.S. collected data; A.E., R.R., M.C., E.M.D. performed the analysis; E.M.D. drafted the manuscript. All authors revised the manuscript for critical intellectual content, contributed to the final manuscript and approve its submission. All authors agree to be accountable for all aspects of the work in ensuring that questions related to the accuracy or integrity of any part of the work are appropriately investigated and resolved. All authors have read and agreed to the published version of the manuscript.

Funding: E.W. received funding from NZAID/MFAT (Ministry of Foreign Affairs and Trade) to travel to study areas. The work was further supported by donations from the Butterfly Trust and the Rotary Club of New Zealand.

Institutional Review Board Statement: The study was conducted according to the guidelines of the Declaration of Helsinki and approved by the ethics committee of Victoria University of Wellington, New Zealand, Ref HEC\#19916. Additionally, permission was granted at each site by local health staff, village chiefs, parents and school staff for clinical examinations of children, with all children consenting to participate. Informed consent was obtained from all subjects involved in the study.

Informed Consent Statement: Informed consent was obtained from all subjects involved in the study.

Conflicts of Interest: E.D. has received honoraria from UCB, Pfizer and Lilly, not relevant to this study. No other authors declare any conflict of interest.

\section{References}

1. Clynes, M.; Harvey, N.; Curtis, E.M.; Fuggle, N.R.; Dennison, E.; Cooper, C. The epidemiology of osteoporosis. Br. Med. Bull. 2020, 133, 105-117. [CrossRef] [PubMed]

2. Chandran, M.; Bhadada, S.; Ebeling, P.; Gilchrist, N.; Khan, A.; Halbout, P.; Lekamwasam, S.; Lyubomirsky, G.; Mitchell, P.; Nguyen, T.; et al. IQ driving QI: The Asia Pacific Consortium on Osteoporosis (APCO): An innovative and collaborative initiative to improve osteoporosis care in the Asia Pacific. Osteoporos. Int. 2020, 31, 2077-2081. [CrossRef] [PubMed]

3. Mohammadi, A.A.; Yousefi, M.; Yaseri, M.; Jalilzadeh, M.; Mahvi, A.H. Skeletal fluorosis in relation to drinking water in rural areas of West Azerbaijan, Iran. Sci. Rep. 2017, 7, 17300. [CrossRef]

4. Ramesh, M.; Malathi, N.; Ramesh, K.; Aruna, R.M.; Kuruvilla, S. Comparative Evaluation of Dental and Skeletal Fluorosis in an Endemic Fluorosed District, Salem, Tamil Nadu. J. Pharm. Bioallied Sci. 2017, 9, S88-S91. [CrossRef] [PubMed]

5. Kebede, A.; Retta, N.; Abuye, C.; Whiting, S.J.; Kassaw, M.; Zeru, T.; Tessema, M.; Kjellevold, M. Dietary Fluoride Intake and Associated Skeletal and Dental Fluorosis in School Age Children in Rural Ethiopian Rift Valley. Int. J. Environ. Res. Public Health 2016, 13, 756. [CrossRef] [PubMed]

6. Liu, G.; Ye, Q.; Chen, W.; Zhao, Z.; Li, L.; Lin, P. Study of the relationship between the lifestyle of residents residing in fluorosis endemic areas and adult skeletal fluorosis. Environ. Toxicol. Pharmacol. 2015, 40, 326-332. [CrossRef] [PubMed]

7. Jarvis, H.G.; Heslop, P.; Kisima, J.; Gray, W.K.; Ndossi, G.; Maguire, A.; Walker, R.W. Prevalence and aetiology of juvenile skeletal fluorosis in the south-west of the Hai district, Tanzania-A community-based prevalence and case-control study. Trop. Med. Int. Health 2012, 18, 222-229. [CrossRef] [PubMed]

8. Melaku, Z.; Assefa, G.; Enqusilassie, F.; Bjorvatn, K.; Tekle-Haimanot, R. Epidemiology of skeletal fluorosis in Wonji Shoa Sugar Estate, Wonji, Ethiopia: A community based survey. Ethiop. Med. J. 2012, 50, 307-313. [PubMed]

9. Oruc, N. Occurrence and problems of high fluoride waters in Turkey: An overview. Environ. Geochem. Health 2008, 30, 315-323. [CrossRef]

10. McGill, P.E. Endemic fluorosis. Bailliere Clin. Rheumatol. 1995, 9, 75-81. [CrossRef]

11. Teotia, M.; Teotia, S.P.S.; Kunwar, K.B. Endemic skeletal fluorosis. Arch. Dis. Child. 1971, 46, 686-691. [CrossRef]

12. Khan, Y.M.; Wig, K.L. Chronic Endemic Fluorosis (With Bone Affections) in the Punjab. Indian Med Gaz. 1945, 80, 429-433.

13. Jolly, S.S.; Singh, B.M.; Mathur, O.C.; Malhotra, K.C. Epidemiological, Clinical, and Biochemical Study of Endemic Dental and Skeletal Fluorosis in Punjab. Br. Med. J. 1968, 4, 427-429. [CrossRef] [PubMed]

14. Jolly, S.; Sing, B.; Mathur, O. Endemic fluorosis in Punjab (India). Am. J. Med. 1969, 47, 553-563. [CrossRef]

15. Petrone, P.P.; Giordano, M.; Giustino, S.; Guarino, F.M. Enduring Fluoride Health Hazard for the Vesuvius Area Population: The Case of AD 79 Herculaneum. PLoS ONE 2011, 6, e21085. [CrossRef]

16. Edmunds, W.M.; Smedley, P.L. Fluoride in natural waters. In Essentials of Medical Geology: Revised Edition; Selinus, O., Ed.; Springer Publishing: New York, NY, USA, 2013. [CrossRef] 
17. Stewart, C.; Damby, D.E.; Tomašek, I.; Horwell, C.J.; Plumlee, G.S.; Armienta, M.A.; Hinojosa, M.G.R.; Appleby, M.; Delmelle, P.; Cronin, S.; et al. Assessment of leachable elements in volcanic ashfall: A review and evaluation of a standardized protocol for ash hazard characterization. J. Volcanol. Geotherm. Res. 2020, 392, 106756. [CrossRef]

18. d'Alessandro, W. Human fluorosis related to volcanic activity: A review. WIT Trans. Biomed. Health 2006, 10, 21-30.

19. Cronin, S.J.; Sharp, D.S. Environmental impacts on health from continuous volcanic activity at Yasur (Tanna) and Ambrym, Vanuatu. Int. J. Environ. Health Res. 2002, 12, 109-123. [CrossRef] [PubMed]

20. Carn, S.A.; Fioletov, V.E.; McLinden, C.; Li, C.; Krotkov, N. A decade of global volcanic $\mathrm{SO}_{2}$ emissions measured from space. Sci. Rep. 2017, 7, srep44095. [CrossRef]

21. Jackson, D.; Murray, J.J.; Fairpo, C.G. Life-long benefits of fluoride in drinking water. Br. Dent. J. 1973, 134, 419-422. [CrossRef] [PubMed]

22. Wang, Y.; Yin, Y.; Gilula, L.A.; Wilson, A.J. Endemic fluorosis of the skeleton: Radiographic features in 127 patients. Am. J. Roentgenol. 1994, 162, 93-98. [CrossRef]

23. Teotia, S.P.S.; Teotia, M. Secondary Hyperparathyroidism in Patients with Endemic Skeletal Fluorosis. Br. Med. J. 1973, 1, 637-640. [CrossRef]

24. Köroğlu, B.K.; Ersoy, I.H.; Köroğlu, M.; Balkarli, A.; Ersoy, S.; Varol, S.; Tamer, M.N. Serum Parathyroid Hormone Levels in Chronic Endemic Fluorosis. Biol. Trace Element Res. 2010, 143, 79-86. [CrossRef] [PubMed]

25. Pandey, A. Prevalence of fluorosis in an endemic village in central India. Trop. Dr. 2010, 40, 217-219. [CrossRef] [PubMed]

26. Horowitz, H.S. Indexes for Measuring Dental Fluorosis. J. Public Health Dent. 1986, 46, 179-183. [CrossRef] [PubMed]

27. Webb, E.; Dennison, E.; Faibairn-Dunlop, P.; Stewart, P. Paediatric Oral Health Burden in Vanuatu Influenced by Volcanogenic Fluoride. 2019. Available online: https:/ /iadr.abstractarchives.com/abstract/19iags-3171751/paediatric-oral-health-burdenin-vanuatu-influenced-by-volcanogenic-fluoride (accessed on 27 July 2021).

28. No Hospital. Available online: http:/ / documents1.worldbank.org/curated/en/802001468125696716/pdf/895050WP0Healt0 0Box385284B00PUBLIC0.pdf (accessed on 27 July 2021).

29. NOHS. National Oral Health Survey of Vanuatu (NOHS) 2018. Report. Ministry of Health Vanuatu, Sailing Ministries, PVC Health Vanuatu. 2017. Available online: https://msm.org.au/launching-of-the-national-oral-health-survey/ (accessed on 27 July 2021).

30. Levy, S.M.; Eichenberger-Gilmore, J.M.; Warren, J.J.; Kavand, G.; Letuchy, E.; Broffitt, B.; Marshall, T.A.; Burns, T.L.; Janz, K.F.; Pauley, C.; et al. Associations of fluoride intake with children's cortical bone mineral and strength measures at age 11. J. Public Health Dent. 2018, 78, 352-359. [CrossRef] [PubMed]

31. Yildiz, M.; Akdogan, M.; Tamer, N.; Oral, B. Bone Mineral Density of the Spine and Femur in Early Postmenopausal Turkish Women with Endemic Skeletal Fluorosis. Calcif. Tissue Int. 2003, 72, 689-693. [CrossRef]

32. Teotia, M.; Teotia, S.P.; Singh, K.P. Endemic chronic fluoride toxicity and dietary calcium deficiency interaction syndromes of metabolic bone disease and deformities in India: Year 2000. Indian J. Pediatr. 1998, 65, 371-381. [CrossRef]

33. Shashi, A.; Kumar, M.; Bhardwaj, M. Incidence of skeletal deformities in endemic fluorosis. Trop. Dr. 2008, 38, $231-233$. 